\title{
A scheme for calculating soil moisture content by using routine weather data
}

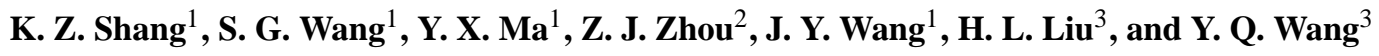 \\ ${ }^{1}$ Gansu Key Laboratory of Climate Change and Reducing Disaster, College of Atmospheric Sciences, Lanzhou University, \\ Lanzhou 730000, P.R. China \\ ${ }^{2}$ National Meteorological Center, CMA, Beijing 100081, P.R. China \\ ${ }^{3}$ Chinese Academy of Meteorological Sciences, CMA, Beijing 100081, P.R. China
}

Received: 5 April 2007 - Published in Atmos. Chem. Phys. Discuss.: 30 May 2007

Revised: 10 September 2007 - Accepted: 28 September 2007 - Published: 9 October 2007

\begin{abstract}
Soil moisture content is one of the most important parameters as input conditions in forecasting model systems of dust storm, but it can not be directly obtained from daily routine weather report. In this paper, a scheme is developed to calculate the surface soil moisture content in China by using both precipitation and evaporation. Precipitation is directly from routine weather report, while evaporation is indirectly calculated by using meteorological elements which are also from routine weather report. According to the formula by Penman, evaporation can be considered as a linear composition of dynamic evaporation and thermodynamic evaporation caused by radiation. First, an equation for calculating daily global radiation within China is given by using regression analysis and the data of global radiation and cloud cover from 116 meteorological stations in China. Then, an equation for calculating evaporation within China is given by using regression analysis and the data of cloud cover, air temperature, precipitation, relative humidity, and wind velocity from 701 meteorological stations. Finally, a scheme for calculating soil moisture content within China is established by using regression analysis and the soil moisture content, precipitation, and evaporation at 79 agro-meteorological stations. Validation results show that the forecasting accuracy of the Chinese dust numerical model can be improved by using this scheme.
\end{abstract}

\section{Introduction}

As a key physical factor in land surface processes, soil moisture content is an important parameter to scientists in many related fields. It plays an important role in adjusting and controlling the interactive processes between the ground and the atmosphere. On the one hand, the thermodynamic character

Correspondence to: K. Z. Shang

(kezheng_shang@yahoo.com.cn) of soil moisture determines Bonn ratio of sub grid processes and causes the flux of sensible heat, latent heat, and long wave radiation from the ground to atmosphere to change, thus influencing climatic changes. On the other hand, the change of soil moisture content itself also affects the thermodynamic character of the soil and the hydrological cycle of the land surface, making various physical and biochemical parameters change accordingly, thus further affecting climatic changes. Research results show that in the processes of climatic changes, the effect of soil moisture is only inferior to that of sea-surface temperature, and it also has an important influence on the formation and variation of regional climate (Yeh et al., 1984; Lin et al., 2001).

In the processes of wind erosion and dust storm development, soil moisture content, by affecting the cohesion between soil particles, influences the threshold friction velocity at which dust particles escape from the surface, and thus influences the amount of dust emitted into the atmosphere from the surface. However, in most sand-dust numerical models developed by Chinese, soil moisture content in China is treated as a constant, namely the climatic mean value, because it can not be directly obtained from routine daily weather report. Obviously this is not reasonable.

Up to now, there have been no directly observed data of routine daily soil moisture content, and calculation of soil moisture content is also very difficult. Because of the importance of soil moisture in synoptic, climatic, and environmental studies, some scholars have studied the distribution characteristics of soil moisture content within local areas based on a limited amount of experimental and observational data (Matsuyama et al., 1997; Li et al., 2000). At the present, the methods for estimating soil moisture content can be divided into three types. The first type is based on the relationship between meteorological factors and soil moisture by using statistical analysis (Clapp et al., 1978; Lu, 1989; Wang et al., 1991; Jin et al., 1998; Reichle et al., 2002; Zhang et al., 2004, 2006), but these studies are mostly limited to local

Published by Copernicus Publications on behalf of the European Geosciences Union. 
areas. The second type is based on the equilibrium equation of soil moisture or hydrodynamic equation (Baier et al., 1966; Campbell et al., 1974; Lei et al., 1988; Pei et al.,1990; Xie et al.,1998, 1999; Shen et al., 2003; Zhang et al.,2006). Because real-time soil moisture content data are hard to get, so the initial values of soil moisture content need to be deduced by using other methods, such as remote sensing. The third type is based on the retrieval of soil moisture content from satellite remote sensing data (Kerstin et al., 1993; Jackson et al., 1996; Lin et al., 1994; Houser et al., 1998; Levitt et al., 1998; Liu et al., 1998; Gao et al., 2001; Yao et al., 2004; Qiao et al., 2006; She et al., 2006). There are many methods for soil moisture monitoring by using remote sensing. They can be divided into two kinds: optical remote sensing and microwave remote sensing. Optical remote sensing, the most widely used kind so far, includes methods such as improved thermal inertia, crop water shortage index (CWSI), and vegetation index. The thermal inertia method is good for bare soil or land surface covered with sparse vegetation, but it suffers from the interference of cloudy weather. So, in practice, remote sensing data within a period of 10 days are usually used to monitor soil moisture. The CWSI and vegetation index methods are good for land surface covered with dense vegetation. But they mainly represent the soil moisture in the root zone. The daily variation of soil moisture is weaker in the root zone than at the surface. So, at present, soil moisture monitoring by remote sensing is manly used in drought monitoring and the climatic evaluation of soil moisture. So, this type is good for drought monitoring and the climatic evaluation of soil moisture, but not so good for daily soil moisture content retrieval. Therefore establishing a reasonable scheme for estimating soil moisture content is an important and urgent task in current synoptic and climatic numerical simulation studies (Sellers, 1996).

Research results show that precipitation is the most important of all meteorological factors which influence soil moisture content (Chen et al., 2005), and the influence of precipitation on surface soil moisture content does not last over a month (He et al., 2002). In this paper we use the Penman formula, statistical analysis, and available meteorological data in China to develop a scheme for calculating daily soil moisture content, with the aim to improve the numerical forecasting accuracy of dust storm events.

\section{Data and research method}

\subsection{Data}

Data used in this study are as follows: (1) the data of soil moisture content 0 to $10 \mathrm{~cm}$ depth, measured by oven drying, from 79 agro-meteorological stations in China between 1981 and 2002; (2) global radiation data from 116 meteorological stations in China between 1961 and 2000; (3) the data of cloud cover, air temperature, precipitation, relative humid- ity, wind velocity and evaporation from 701 meteorological stations in China between 1961 and 2002.

\subsection{Research method}

The most important factors affecting soil moisture content are precipitation and evaporation. In geography and climatology, the ratio of annual (or monthly) precipitation to annual (or monthly) evaporation is used to indicate the wetness of soil (Liu et al., 2000). Based on the same principle, the ratio of daily precipitation to evaporation can also be used to calculate daily soil moisture.

In routine weather report, precipitation is given directly, but not evaporation. However, it can be calculated by using of other meteorological elements. According to the Penman formula (Chen et al., 1993), evaporation can be calculated as follows:

$$
\begin{aligned}
& E_{T}=C\left(E_{h}+E_{m}\right) \\
& E_{h}=\frac{\Delta}{\gamma+\Delta} \frac{R_{S}}{L} \\
& E_{m}=\frac{\Delta}{\gamma+\Delta}[0.37(1+\mathrm{V} / 160)]\left(e_{s}-e_{a}\right) \\
& e_{s}=e_{0} \exp \left(\frac{a t}{273.16+t-b}\right) \\
& e_{a}=r h \bullet e_{s} \\
& R_{s}=(1-\alpha) Q-F
\end{aligned}
$$

where $E_{T}$ is total evaporation, $E_{h}$ is thermodynamic evaporation, $E_{m}$ is dynamic evaporation, $\Delta=\frac{e_{a}}{T_{a}}\left(\frac{6463}{T_{a}}-3.927\right)$, $\gamma=\frac{C_{p} P_{s}}{0.622 L}, R s$ is net radiation, $L$ is the latent heat of vaporization per unit mass, $V$ is wind velocity, $e_{a}$ is actual vapor pressure, $e_{s}$ is saturation vapor pressure, $a, b$, and $e_{0}$ is constant, $t$ is air temperature, $r h$ is air relative humidity, $\alpha$ is surface albedo, $Q$ is global radiation, and $F$ is effective radiation.

According to Eq. (6), $\alpha$ and $F$ are needed to calculate $R s$, but they can't be obtained directly from routine weather report. Generally, effective radiation $F$ is proportional to global radiation, and surface albedo $\alpha$ is proportional to vegetation cover rate and indirectly related to global radiation. In order to simplify the calculation, net radiation $R_{S}$ can be assumed proportional to global radiation

$$
R_{S}=D_{0}+D_{1} Q
$$

Replacing (6) with (7), we get:

$$
\begin{aligned}
E_{T} & =C \frac{\Delta}{\gamma+\Delta}[0.37(1+V / 160)]\left(e_{s}-e_{a}\right) \\
& +C \frac{\Delta}{\gamma+\Delta} \frac{D_{0}+D_{1} Q}{L}
\end{aligned}
$$




$$
\begin{aligned}
& =C \frac{\Delta}{\gamma+\Delta} \frac{D_{0}}{L}+C \frac{\Delta}{\gamma+\Delta}[0.37(1+V / 160)]\left(e_{s}-e_{a}\right) \\
& +C \frac{\Delta}{\gamma+\Delta} \frac{D_{1} Q}{L}
\end{aligned}
$$

Let: $B_{0}=C \frac{\Delta}{\gamma+\Delta} \frac{D_{0}}{L}$

$$
\begin{aligned}
& B_{1}=C \frac{\Delta}{\gamma+\Delta} \\
& \mathrm{B}_{2}=C \frac{\Delta D_{1}}{\gamma+\Delta} \\
& E_{1}=\left[0.37\left(1+\frac{V}{160}\right)\right]\left(e_{s}-e_{a}\right) \\
& E_{2}=\frac{Q}{L}
\end{aligned}
$$

then $E_{T}=B_{0}+B_{1} E_{1}+B_{2} E_{2}$

where $E_{1}$ can be calculated by ground wind speed, air temperature and air relative humidity, and $E_{2}$ can be calculated by global radiation and the latent heat of vaporization per unit mass $L$. But the value of $C, D_{0}$, and $D_{1}$ is uncertain. For this reason, $B_{0}, B_{1}$, and $B_{2}$ need to be calculated by statistical regression

There are no radiation data at most meteorological stations in China, so we need to calculate global radiation $Q$. When solar radiation enters into the atmosphere, it is usually weakened by the reflection and absorption due to many meteorological factors, among which cloud is the most important. So global radiation can be calculated as follows:

$Q=S_{0}\left[1-\left(A_{0}+A_{1} C_{n}+A_{2} C_{L}\right)\right]$

where $C_{n}$ is total cloud cover, $C_{L}$ is low cloud cover, and $S_{0}$ is astronomical radiation. $A_{0}, A_{1}$ and $A_{2}$ can be calculated by statistical regression. $S_{0}$ can be calculated as follows (Wen, 1997):

$$
\begin{aligned}
S_{0} & =\int_{-t_{0}}^{t_{0}} \frac{I_{0}}{\rho^{2}} \sinh _{\Theta} d t \\
& =\int_{-t_{0}}^{t_{0}} \frac{I_{0}}{\rho^{2}}(\sin \varphi \sin \delta+\cos \varphi \cos \delta \cos \omega) d t
\end{aligned}
$$

where $I_{0}$ is the solar constant and is equal to $1367 \mathrm{~W} / \mathrm{m}^{2}, h_{\Theta}$ is solar altitude angle, $\frac{1}{\rho^{2}}$ is the correction to the average sunearth distance, $\varphi$ is geographical latitude, $\delta$ is declination, $\omega$ is the azimuth angle of the sun, $-t_{0}$ is the time of sunrise, and $t_{0}$ is the time of sunset. From Eq. (12) we have:

$S_{0}=\frac{T I_{0}}{\pi \rho^{2}}\left(\omega_{0} \sin \varphi \sin \delta+\cos \varphi \cos \delta \sin \omega_{0}\right)$

where $T=86400 s,-\omega_{0}$ is the azimuth angle of sunrise, and $\omega_{0}$ is the azimuth angle of sunset.

$\omega_{0}=\arccos (-\operatorname{tg} \varphi \operatorname{tg} \delta)$ $\frac{1}{\rho^{2}}$ and $\delta$ can be calculated as follows:

$$
\begin{aligned}
\frac{1}{\rho^{2}}= & 1.00011+0.03422 \cos \theta_{0}+0.00128 \sin \theta_{0} \\
& +0.000719 \cos 2 \theta_{0}+0.000077 \sin 2 \theta_{0}
\end{aligned}
$$

$$
\begin{aligned}
\delta & =0.006918-0.399912 \cos \theta_{0}+0.070257 \sin \theta_{0} \\
& -0.006758 \cos 2 \theta_{0}+0.000907 \sin 2 \theta_{0} \\
& -0.0002697 \cos 3 \theta_{0}+0.000148 \sin 3 \theta_{0}
\end{aligned}
$$

where $\theta_{0}=2 \pi\left(d_{n}-1\right) / 365, d_{n}$ is the order number of the day, counted from 1 January to 31 December.

To sum up the above discussion, a scheme for calculating soil moisture content in China can be developed according to the following four steps:

First, a method for calculating daily solar radiation $Q$ can be established by using global radiation and cloud data available from some meteorological stations in China.

Second, a method for calculating total evaporation $E_{T}$ can be set up by using dynamic evaporation $E_{1}$ and the thermodynamic evaporation $E_{2}$ which can be calculated from routine meteorological elements available from some meteorological stations in China.

Third, a scheme for calculating soil moisture content can be established by using the data of precipitation, total evaporation, and soil moisture content available from some agrometeorological stations in China.

Fourth, validation of the established scheme.

\section{Establishment of the scheme for calculating soil mois- ture content}

\subsection{Calculation of global radiation}

There are only 116 meteorological stations in China with available global radiation data. By using the data of total cloud cover, low cloud cover and global radiation from the 116 meteorological stations, we get the coefficients $A_{0}, A_{1}$, and $A_{2}$ for these stations through statistical regression based on equation (11). The results show that the value of the multiple correlation coefficient $R$ of this regression equation is from 0.5715 to 0.8592 . All regression equations of the 116 meteorological stations can pass the significance test at the level of $\alpha=0.001$. The coefficients $A_{0}, A_{1}, A_{2}$ at the 116 meteorological stations are different from each other, but they are all related to latitude, longitude, elevation, annual mean temperature, annual precipitation, annual mean total cloud cover, and annual mean low cloud cover (denoted by $x_{1}, x_{2}, \ldots x_{7}$ respectively, and the same applies below) from 116 meteorological stations. By using the above parameters 


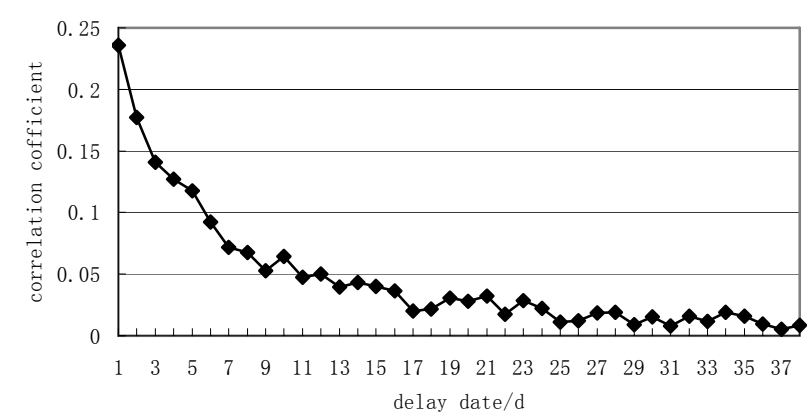

Fig. 1. Average delay-cross-correlation coefficients between precipitation and soil moisture for 79 agro-meteorological stations in China.

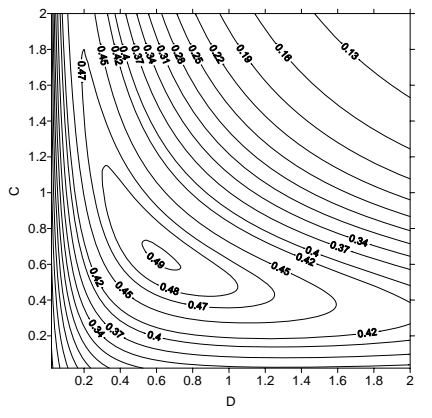

(a)

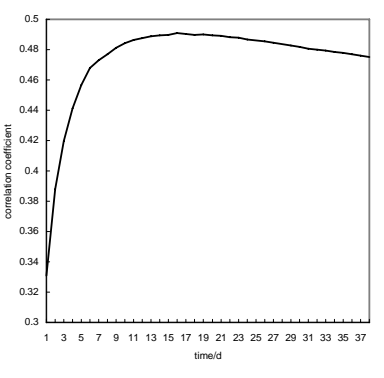

(b)
Fig. 2. Average correlation coefficient of soil moisture content and the compound effect of precipitation and evaporation for the 79 agro-meteorological stations in China. (a. correlation coefficient distribution with $C$ and $D$ when $N=16$. b. correlation coefficient variation with $N$ when $C=0.64, D=0.62$.)

as independent variables and $A_{0}, A_{1}, A_{2}$ as dependent variables, we get a group of regression equations as follows:

$$
\begin{aligned}
A_{0} & =0.17412+0.0010343 x_{2}-0.0000197 x_{3} \\
& +0.0055469 x_{4}-0.0000501 x_{5} \quad R=0.7494 \\
A_{1} & =0.01392-0.0011179 x_{4}+0.0000103 x_{5} \\
& +0.0065975 x_{6}-0.0064179 x_{7} \quad R=0.7840 \\
A_{2} & =0.01810-0.0000015 x_{3}+0.0004412 x_{4} \\
& -0.0024786 x_{6}+0.0043320 x_{7} \quad R=0.7589
\end{aligned}
$$

It can be seen clearly that Eq. (17) also passes the significance test at the level of $\alpha=0.001$. Putting Eq. (17) into Eq. (11), we can calculate daily global radiation in China by using daily cloud cover data.

\subsection{Calculation of evaporation}

By using the data of daily wind velocity $V$, air temperature $t$, and air relative humidity $r h$ from 701 meteorological stations in China, based on Eqs. (4), (5), and (8), we obtain dynamic evaporation $E_{1}$ for the 701 meteorological stations.

By using the data of daily cloud cover from 701 meteorological stations in China, based on Eqs. (13) to (16), (11), and (9), we obtain daily thermodynamic evaporation $E_{2}$ for the 701 meteorological stations.

By using the data of daily observed evaporation, $E_{1}$, and $E_{2}$ for the 701 meteorological stations, the coefficients $B_{0}, B_{1}, B_{2}$ and multi-correlation coefficient $R$ of the 701 meteorological stations can be obtained based on equation (10) through statistical regression. The value of $R$ ranges from 0.73 to 0.97 , so all the regression equations pass the significance test at the level of $\alpha=0.001$. The coefficients $B_{0}, B_{1}, B_{2}$ (dependent variables) of the 701 meteorological stations are different from each other, but they are also related to $x_{1}, x_{2}, \ldots x_{7}$ (independent variables). By using regression analysis we get a group of regression equations as follows:

$$
\begin{aligned}
B_{0} & =3.77802-0.063042 x_{1}-0.011743 x_{2} \\
& -0.000454 x_{3}-0.085141 x_{4}+0.000552 x_{5} R=0.7331 \\
B_{1} & =3.86344-0.056688 x_{1}+0.008792 x_{2} \\
& -0.095390 x_{4}-0.000092 x_{5} R=0.8636 \\
B_{2} & =+0.74944-0.002038 x_{2}+0.008871 x_{4} \\
& -0.000068 x_{5}-0.039797 x_{6} R=0.6656
\end{aligned}
$$

It can be seen clearly from (18) that the equations also pass the significance test at the level of $\alpha=0.001$. By putting (18) into (10), daily total evaporation in China can be calculated by using daily cloud cover, wind velocity, air temperature, and air relative humidity.

\subsection{Calculation of soil moisture}

In China there are only 79 agro-meteorological stations with available soil moisture data (non- routine weather report). Based on equation (4) to (5), (13) to (16), (11), (18), and (8) to (10), we can calculate evaporation for the 79 agrometeorological stations, By using the data of daily cloud cover, wind velocity, air temperature, and air relative humidity from the 79 agro-meteorological stations.

According to the above discussion, soil moisture content can be calculated by using the ratio of daily precipitation to daily evaporation. The influence of precipitation on soil moisture content declines with time. Figure 1 shows the average delay-cross-correlation coefficients between precipitation and soil moisture for 79 agro-meteorological stations in China. In other words, the influence of precipitation on the day which is $K$ days ago on soil moisture is also related to the sum of evaporation since then. Thus, the combined effect of precipitation and evaporation can be defined as follows:

$$
Z_{K}=\frac{P_{K}}{\sum_{j=1}^{K} E_{T_{J}}}
$$

where $P_{k}$ is precipitation of $K$ days ago, $E_{T j}$ is evaporation of $j$ days ago. The compound influence of all the precipitation events and evaporation in the past $N$ days on soil moisture content can be defined as follows:

$X=\left(\sum_{K=1}^{N}\left(Z_{K}\right)^{C}\right)^{D}$ 
In order to obtain the best values of $N, C$, and $D$, we first take $C=0.02,0.04,0.06, \cdots, 2.0 ; D=0.02,0.04,0.06, \cdots, 2.0$; and $N=1,2,3, \cdots, 38$; then we calculate the daily value of $X$ for the 79 available agro-meteorological stations in China by using Eq. (20). And then the correlation coefficient between $X$ and soil moisture content is calculated. Calculation results show that when $N=16, C=0.64$, and $D=0.62$, the average value of the correlation coefficients of the 79 agro-meteorological stations is the greatest (0.4909) (see Fig. 2)

From Fig. 1, it can be seen that when lag time is more than 7 days, the delay-cross-correlation coefficients between precipitation and soil moisture becomes so low that it can't pass the significance test at the level of $\alpha=0.1$ (average samples $=448$, so, $r_{c}=0.078$ ). But this don't mean the influence of precipitation on soil moisture does not go beyond 7 days. When we use the compound factor X (see Eqs.19 and 20) to consider the influence of precipitation on soil moisture, we find the cumulated influence reaches it maximum value at 16 days.

As a result, Eq. (20) can be concretely expressed as follows:

$X=\left(\sum_{K=1}^{16}\left(\frac{P_{K}}{\sum_{j=1}^{K} E_{T_{J}}}\right)^{0.64}\right)^{0.62}$

Assuming that soil moisture content has a linear relationship with $\mathrm{X}$, we have

$S=A+B X$

where $S$ is soil moisture content, while $A$ and $B$ can be obtained through regression analysis. The values of $A$ and $B$ of the 79 agro-meteorological stations are different from each other, but they are all related to longitude $\left(x_{2}\right)$, annual mean temperature $\left(x_{4}\right)$, annual precipitation $\left(x_{5}\right)$, and total cloud cover $\left(x_{6}\right)$. By using regression analysis, we can obtain the values of $\mathrm{A}$ and $\mathrm{B}$ as follows:

$$
\begin{array}{ll}
A=1.21-0.758 x_{4}+0.018 x_{5}+1.81 x_{6} & R=0.6742 \\
B=6.56-0.04 x_{2} & R=0.5332
\end{array}
$$

It can be seen clearly from (23) that the equations pass the significance test at the level of $\alpha=0.001$. Based on Eqs. (4) to (5), (13) to (16), (11), (18), (8) to (10), and (21) to (23), the daily soil moisture content in China can be calculated by using the data of daily cloud cover, wind velocity, air temperature, air relative humidity and precipitation from routine weather report.

However, sometimes one or two of the meteorological elements needed for the above calculations is not available in routine weather reports, so simplified schemes are needed to replace the original scheme. Three kinds of simplified schemes are given as follows:

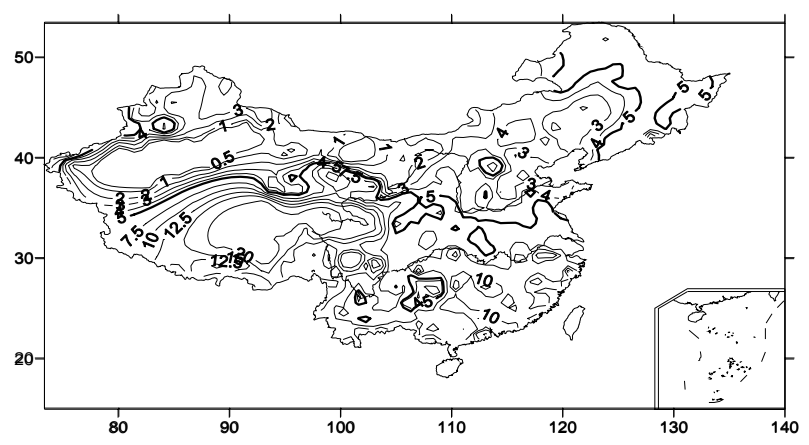

Fig. 3. Soil moisture content distribution when there is no rain for a long time.

1) Scheme without cloud data

When cloud data are absent, only $E_{1}$ can be calculated. The compound effect $X$ is given as follows:

$$
\begin{aligned}
& X=\left(\sum_{K=1}^{12}\left(\frac{P_{K}}{\sum_{j=1}^{K} E_{1 j}}\right)^{0.6}\right)^{0.6} \\
& A=1.50-0.732 x_{4}+0.018 x_{5}+1.771 x_{6} R=0.6786 \\
& B=4.45-0.029 x_{2} R=0.6762
\end{aligned}
$$

2) Scheme with only cloud cover and precipitation

If there are only cloud cover and precipitation, only $E_{2}$ can be calculated. The compound effect $X$ is given as follows:

$$
\begin{aligned}
& X=\left(\sum_{K=1}^{16}\left(\frac{P_{K}}{\sum_{j=1}^{K} E_{2 j}}\right)^{0.70}\right)^{0.68} \\
& A=1.02-0.736 x_{4}+0.018 x_{5}+1.84 x_{6} R=0.6768 \\
& B=9.81-0.061 x_{2} R=0.5902
\end{aligned}
$$

3) Scheme with only precipitation

We have to consider evaporation as constant when only precipitation is available. The compound effect $X$ is given as follows:

$$
\begin{aligned}
X & =\left(\sum_{K=1}^{12}\left(\frac{P_{K}}{K}\right)^{0.70}\right)^{0.74} \\
A & =0.87-0.738 x_{4}+0.018 x_{5}+1.96 x_{6} R=0.6876 \\
B & =3.68-0.023 x_{2} R=0.6189
\end{aligned}
$$

According to Eq. (22), the value of $A$ in Eqs. (23), (25), (27) and (28) should be the lowest soil moisture content. 

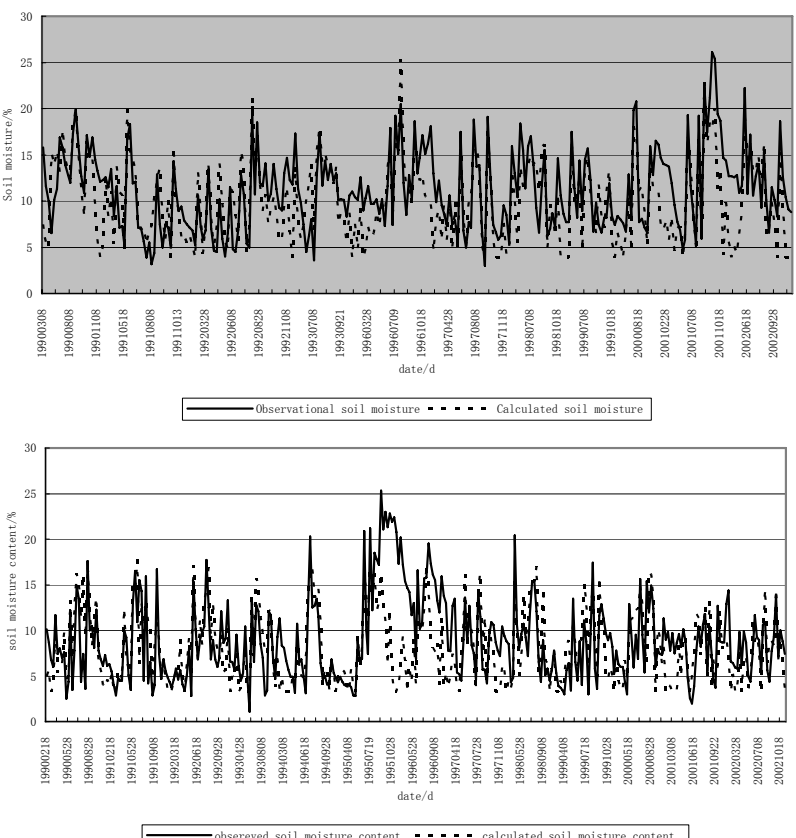

Fig. 4. Observed and calculated soil moisture of 2 stations in China from 1990 to 2002 (a HuanXian; b HuaiLai).

But, it's not the case in reality. The value of $A$ is higher than the lowest soil moisture content (LSM) for the 79 agrometeorological stations. In order to fit the situation in which there is no rain for a long time, Eq. (22) needs to be modified.

Let: $R A=A / L S M$

Through statistical analysis, we find $R A$ is correlated with altitude $\left(\mathrm{x}_{3}\right)$, so we get:

$R A=3.0-0.0005 x_{3}$

Therefore, Eq. (22) can be modified as follows:

$S=A / R A+R A \bullet B X$ when $<A / B / R A$ or $R A<=1$

$S=A+B X$ when $X>=A / B / R A$ and $R A>1$

Figure 3 shows the distribution of the lowest soil moisture content in China calculated by using Eqs. (23) (30) and (31). It can be seen that the lowest soil moisture content is less than $5 \%$ in northern China and most part of western China except Northeast China. Specially, it is less than $0.5 \%$ in the Taklimakan Desert. The results calculated by using Eqs. (25), (27), and (29) are very similar to that shown in Fig. 3

Test by using historical data from 1981 to 2002 for the 79 agro-meteorological stations shows that the average error is between $2 \%$ and $16 \%$ for the 79 agro-meteorological stations in China. Of the 79 stations, there are $35.8 \%$ stations whose average error is less than $5 \%$, and there are $81.5 \%$ stations whose average error is less than $10 \%$. Figure 4 shows a comparison between the soil moisture observed and that calculated by using the modified scheme for 2 agro-meteorological
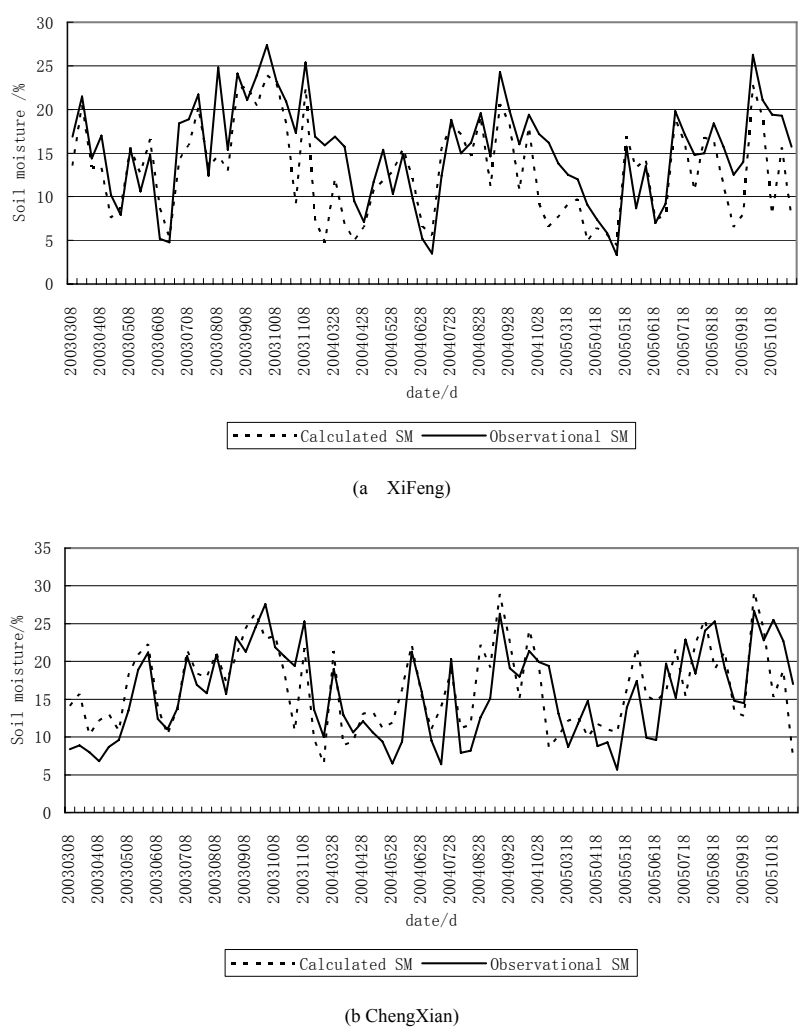

Fig. 5. The comparison between observed and calculated soil moisture in the east of Gansu from 2003 to 2005 (a Xifeng b Chengxian).

stations in China from 1990 to 2002. It can be seen that the calculated soil moisture accords well with the observed soil moisture. This demonstrates that the modification of Eq. (22) by using Eq. (30) and (31) is reasonable.

\section{Validation and application}

\subsection{Validation with observational soil moisture}

In order to validate the established scheme for calculating soil moisture, calculated and observed soil moisture content data from 2003 to 2005 are compared for 7 agrometeorological stations in the east of Gansu Province in China (see Table 1). The results show that the correlation coefficients of 6 stations pass the significance test at the level of $\alpha=0.001$, but that of the Maqu station only passes the significance test at the level of $\alpha=0.01$. The variation of calculated soil moisture content from 2003 to 2005, for 7 agro-meteorological stations in the east of Gansu Province in China, accords well with the variation of observed soil moisture content. Figure 5 shows the calculated and observed soil moisture content time series of Xifeng and ChengXian from 2003 to 2005 . This demonstrates that the established scheme can be used to calculate ground soil moisture content. 


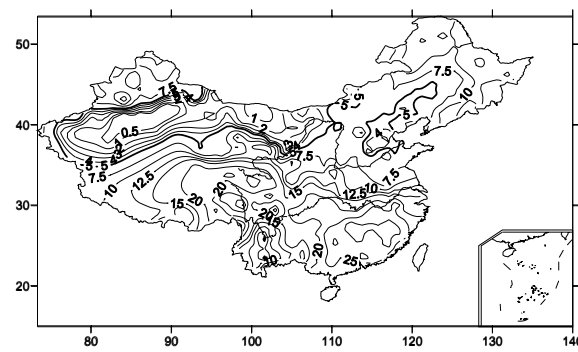

(a)

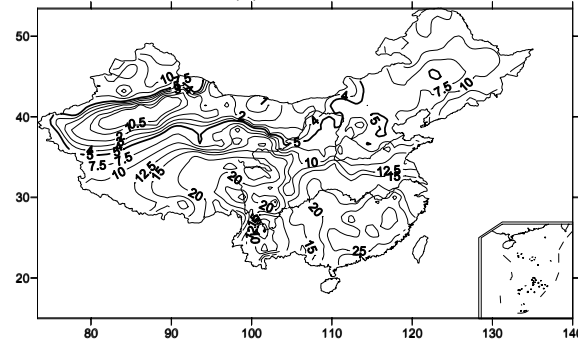

(c)

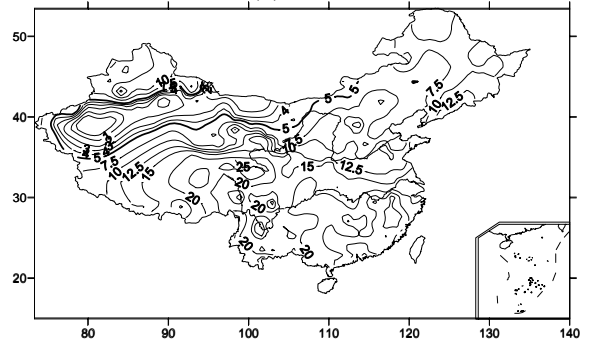

(e)

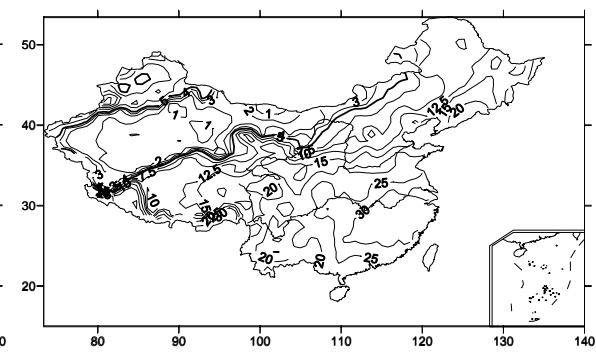

(b)

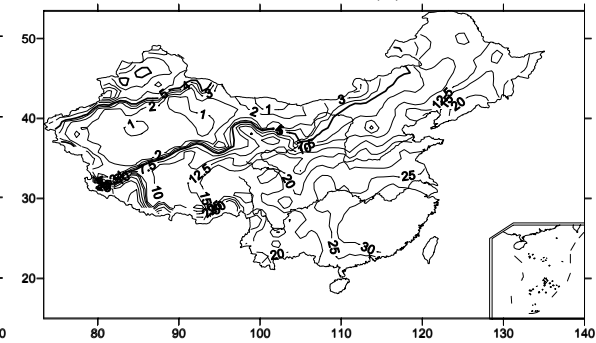

(d)

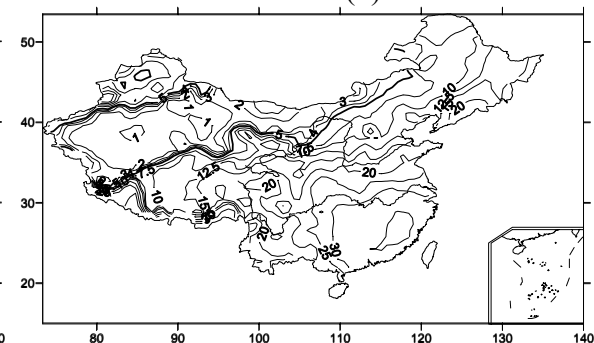

(f)

Fig. 6. The comparison of the soil moisture calculated by our scheme with that from NOAA CPC in China during March 2006 to May 2006 (a, c, e, calculated by our scheme; b, d, f, from NOAA CPC; a, b, March 2006; c, d, April 2006; e, f, May. 2006).

Table 1. Correlation coefficients between estimated and observed soil moisture content at 7 ago-meteorological stations in the east of Gansu.

\begin{tabular}{llllllll}
\hline ago-meteorological station & Dingxi & Huanxian & Xifeng & Tongwei & Maqu & Tianshui & Chengxian \\
\hline Latitude $/\left({ }^{\circ} \mathrm{N}\right)$ & 35.58 & 36.58 & 35.73 & 35.22 & 34.00 & 34.57 & 33.75 \\
Longitude/ $\left({ }^{\circ} \mathrm{E}\right)$ & 104.62 & 107.30 & 107.63 & 105.23 & 102.08 & 105.87 & 105.72 \\
Correlation coefficient & 0.662 & 0.759 & 0.800 & 0.748 & 0.337 & 0.688 & 0.717 \\
Numbers of samples & 75 & 75 & 75 & 75 & 75 & 75 & 75 \\
\hline
\end{tabular}

4.2 Compare to the soil moisture estimated by hydrological model of NOAA CPC

In NOAA climate prediction center (CPC), global soil moisture is estimated by a one-layer (1.6 m in thickness) hydrological model. The unit for soil moisture is millimeter $(\mathrm{mm})$. Global monthly soil moisture can be downloaded from NOAA CPC. Dividing this monthly soil moisture by 1600 , we get soil moisture in percentage. Figure 6 shows the comparison between calculated monthly soil moisture by our scheme and that from NOAA CPC during March 2006 to May 2006. It can be seen that the distribution of calculated soil moisture in China is very similar to that from NOAA
CPC. The isoline of soil moisture content at 5\% in Figs. 6a, $\mathrm{c}$, and e accords well with that in Figs. 6b, d, and f. In northwest China (with the exception of north Xingjiang) and middle Inner Mongolia, the monthly soil moisture calculated by our scheme and that from NOAA CPC are both less than 5\% from March 2006 to May 2006. The soil moisture calculated by our scheme is less than that from NOAA CPC in most part of China, especially in northeast China and the west of Qinghai-Tibetan plateau. In spring, sand dust frequently occurs in North China, so the soil moisture calculated by our scheme may be closer to reality than that from NOAA CPC for sand dust forecasting. 


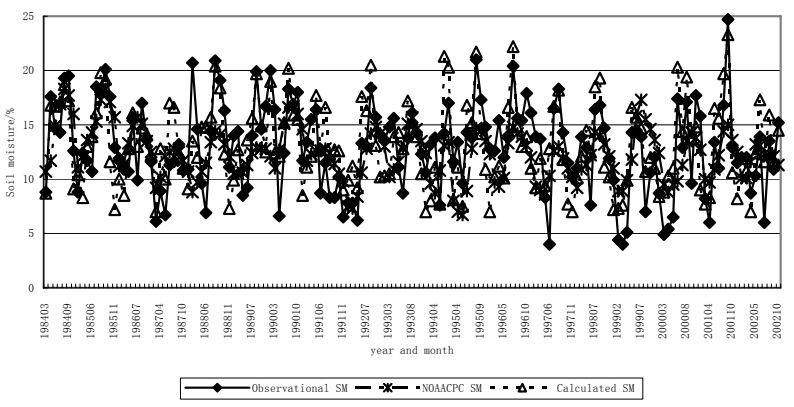

(a) GuYuan

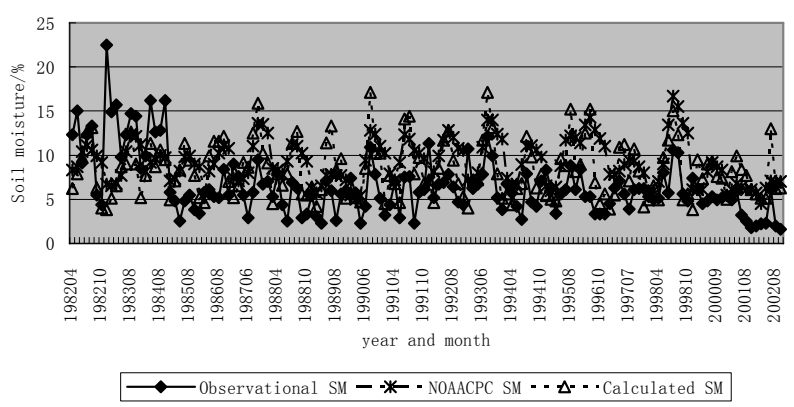

(b) Xilinhaote

Fig. 7. The variation of soil moisture observed, that calculated by using our scheme, and that from NOAA CPC between 1990 and 2002 (a GuYuan; b Xilinhaote).

Figure 7 shows the variation of the soil moisture actually observed, the soil moisture calculated by using our scheme, and the soil moisture downloaded from NOAA CPC from 1990 to 2002 for 2 stations in North China. It can be seen that the soil moisture calculated by using our scheme accords better than that from NOAA CPC with the observed soil moisture, especially when observed moisture is low.

\subsection{Validation of the scheme}

From 8 to 11 April 2006, a strong dust storm event occurred in North China and Mongolia. We have simulated this dust storm event by using the CUACE/Dust system. Figure 8 shows the actual dust storm distribution and simulated dust flux distribution at 10 April 2006, 06:00 (UTC), with two soil moisture values as input conditions for the simulation. It can be seen that the sand dust occurred in two areas. The first area was in South Mongolia and North China. For this area, the dust flux simulated in Fig. $8 \mathrm{c}$ is closer to the actual sand-dust distribution than that simulated in Fig. 8b. The second area was in the Taklimakan. For this area, the simulated results by using both soil moisture values are all close to the actual sand-dust distribution.. The above results show that the forecasting accuracy of the CUACE/Dust system for East China can be improved by using our scheme. Because the accuracy of sand-dust forecasting in East China is more important than that in West China, so our scheme can be used to improve the CUACE/Dust system.

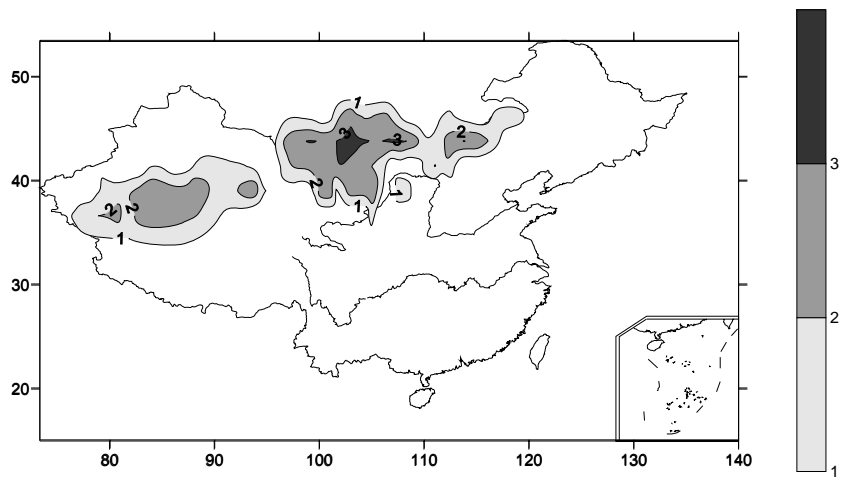

(a)

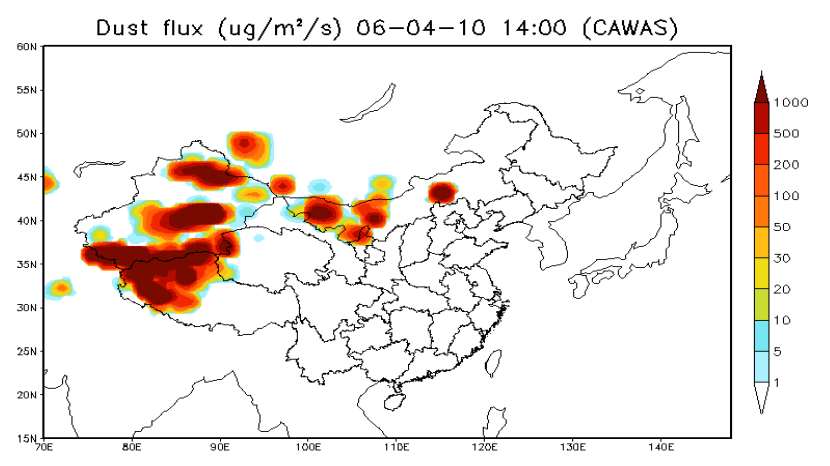

(b)

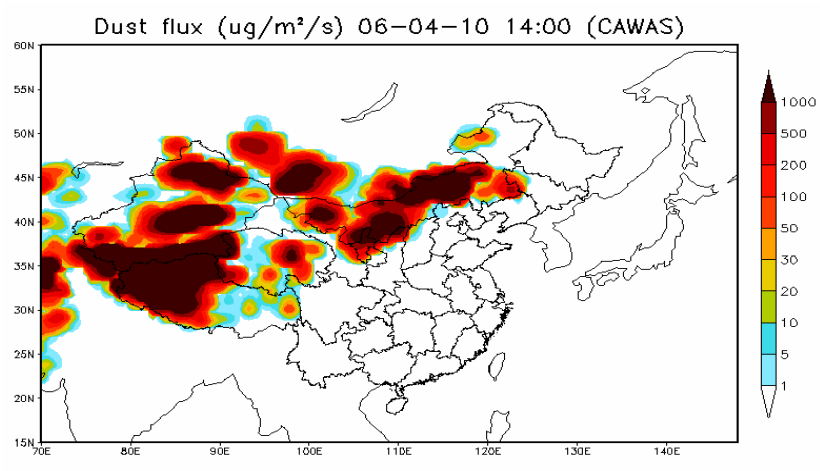

(c)

Fig. 8. The actual dust storm distribution and simulated dust flux distribution with two kind soil moisture contents as input condition at 10 April 2006, 06:00 (UTC). (a the actual dust storm distribution. $1,2,3$ represent actual floating dust, blowing sand and dust storm respectively; b the simulated result with original soil moisture contents as input condition; $\mathbf{c}$ the simulated result with soil moisture contents calculated according to our scheme as input condition) 


\section{Conclusions}

(1) The influence of precipitation on surface soil moisture content can reach to 16 days.

(2) The compound effect of the ratio of precipitation to evaporation, which is non-linearly summed, can be used to calculate the surface soil moisture content in China.

(3) Validation results show that our scheme can be used to calculate soil moisture content in China satisfactorily.

(4) Application results show that the forecasting accuracy of dust storm events in China can be improved by using our soil moisture scheme.

Acknowledgements. The research is supported by the National Basic Research Program of China (2006CB403701), the Project of National Natural Science Foundation of China (40675077), and the Specially Project of Basic Research in China (2006FY110800). We would like to thank S. Gong for his help with this paper.

Edited by: S. Gong

\section{References}

Peng, S. F.: Soil moisture content analysis on the area of Hui-he river and Shi-guan river: Study of energy and water cycle on the area of Hui-he river, Meteorological press, Beijing, 182-186, 1999.

Baier, W. and Robertson, G. W.: A new versatile soil moisture budget, Canadian J. Plant Sci., 46, 299-315, 1966.

Campbell, G. S.: A simple method for determining unsaturated conductivity from moisture retention data, Soil Sci., 117-311, 1974.

Chen, B., Ding, Y. G., and Liu J. M.: The Soil moisture Prediction Model Experiment Research of The Climatic Humid Zone, Scientia Meteorological Sinica, 25(5), 231-237, 2005.

Chen, Q. and Chen ,T. Y.: Estimation of River Basin evapotranspiration over Complex Terrain Using NOAA AVHRR Data, Acta Geographica Sinica, 48(1),61-69, 1993.

Clapp, R. R. and Honberger, G. M.: Empirical equations for soil hydraulic properties, Water Resour. Res., 14, 601-604, 1978.

Gao, F., Wang, J. M., Sun, C. Q., and Wen, J.: Advances in Study on Microwave Remote Sensing of Soil Moisture, Remote Sensing Technology and Application, 16(2), 97-102, 2001.

He, Z. B. and Zhao, W. Z.: Variability of Soil Moisture of Shifting Sandy Land and Its Dependence on Precipitation in Semi-arid Region, J. Desert Res., 22(4), 359-402, 2002.

Houser, P. R., Shuttle, W. J., Famiglietti, J. S., et al.: Integration of soil moisture remote sensing and hydrologic modeling using data assimilation, Water Resour. Res., 34(12), 405-420, 1998.

Jackson, T. J.: Measuring surface soil moisture using passive microwave remote sensing, Hydrol. Processes, 7, 139-152, 1993.

Jackson, T. J., Schmugge, T. J., and Engman, E. T.: Remote sensing applications to hydrology: Soil moisture, Hydrol. Sci. J., 41(4), 517-530, 1996.

Jin, L., Luo, Y., Miao, Q. L., and Shen, S. H.: Forecast Model of Farmland Soil Moisture by Artificial Neural Network, Acta Pedologica Sinica, 35(1), 25-32, 1998.
Kerstin, R., Leif, K., Sune, A., and Thomas, R.: Estimates of denitrification in soil by remote sensing of thermal infrared emission at different moisture levels, Biology and Fertility of Soils, 16(3) 193-197, 1993.

Lei, Z. D., Yang, S. X., and Xie, S. C.: Soil Water Dynamics, TsingHua University Press, Beijing, 1988.

Levitt, D. G., Simpson, J. R., and Huete, A. R.: Estimates of surface soil water content using linear combinations of spectral wavebands, Theoretical and Applied Climatology, 42(4), 245-252, 1990.

Li, Y. and Liu, J. J.: Advance in Spatial Variability of Soil Properties, Journal of Shihezi University (Natural Science), 4(4), 331337, 2000.

Lin, D. S., Wood, E. F., Troch, P. A., et al.: Comparisons of remotely sensed and model simulated soil moisture over a heterogeneous watershed, Remote Sensing of Environment, 48, 159$171,1994$.

Lin, Z. H., Yang, X. S., and Guo, Y. F.: Sensitivity of Land Surface Model to the Initial Condition of Soil Moisture, Clim. Environ. Res., 6(2), 240-248, 2001.

Liu, C. M., Yue, T. X., and Zhou, C. H.: Geographical mathematics model and application, Science press, Beijing, 2000.

Liu, J. Y., Liu, C. S., and Zhang, W. Z.: A Method of Calculating Surface Moisture From GMS and AVHRR, Quart. J. Appl. Meteorol., 9(2), 197-204, 1998.

Lu, Y. B.: Study on the Model for Soil Moisture Forecast in the Three-River Plain Region, Acta Pedologica Sinica, 26(1), 51-56, 1989.

Matsuyama, K. M.: Estimates of continental-scale soil wetness and comparison with the soil moisture data of Mintz and Serafini, Clim. Dyn., 13(10), 681-689, 1997.

Pei, B. X., Mao, F., and Liu, H. Q.: North China spring the soil moisture development imitates the on trial research that forecast the mode, Journal of China Agricultural University, 16(sup.), 116-122, 1990.

Qiao, P. L., Zhang J. X., and Wang, C. H.: Soil moisture retrieving by passive microwave remote sensing data, Journal of Liaoning Technical University, 25(3), 342-344, 2006.

Reichle, R. H., Walker, J. P., and Randal, D. K.: Extended versus ensemble Kalman filtering for land data assimilation, J. Hydrometeorol., 3, 728-740, 2002.

Sellers, A.: Soil Moisture: a critical focus for global change studies, Global and Planetary Change, 13, 39-40, 1996.

She, W. M. and Ye, C. H.: Review on Soil Moisture and Drought Remote Sensing Monitoring Based MODIS Satellite Data, HeNan meteorology, 44-46, 2006.

Shen, H. J., Yan, C. R., and Dai, Y. P.: Progress and application of soil moisture monitoring and forecast models, Ecologic Sci., 22(4), 366-370, 2003.

Wang, F. T., Feng, D. Y., and Zhang, H. M.: Introduction of Agrometeorological forecasting, Agriculture press, Beijing, 1991.

Wen, D. M.: China radiates weather, Meteorological press, Beijing, 1997.

Xie, Z. H., Luo, Z. D., Zeng, Q. C., et al.: A numerical simulation solving moisture content and flux for an unsaturated soil water flow problem, Progress in Natural Sciences, 9(12), 280 286, 1999.

Xie, Z. H., Zeng, Q. C., Dai, Y. J., et al.: Numerical simulation of an unsaturated flow equation, Sciences in China Series D, 28 (4), 
175-180, 1998.

Yao, C. S., Zhang, Z. X., and Wang, X.: Evaluating Soil Moisture Status in XinJiang Using the Temperature Vegetation Dryness Index (TVDI), Remote Sensing Technology and Application, 19(6), 473-478, 2006.

Yeh, T. C., Wetherald, R. I., and Manabe, S.: The effect of soil moisture on the short term climate and hydrology change-A numerical experiment, Monthly Weather Review, 112, 474-490, 1984.

Zhang, S. L., Xie, Z. H., Tian, X. J., et al.: A Soil Moisture Assimilation Scheme With an Unsaturated Soil Water Flow Model and In Site Observation, Advances In Earth Science, 21(12), 13501362, 2006.
Zhang, S. W., Qiu, C. J., and Xu, Q.: Estimating soil water contents from soil temperature measurements by using adaptive Kalman filter, J. Appl. Meteorol., 43, 379-389, 2004.

Zhang, S. W., Li, H. R., Zhang, W. D., et al.: Estimating the soil moisture profile by assimilating near-surface observations with the Ensemble Kalman Filter(EnKF), Adv. Atmos. Sci., 22(6), 936-945, 2006. 